\title{
Impact of IT Techniques on Human Resource Management in Technical Institutes of India
}

\author{
Dr. Seema Shah \\ Indian Institute of Information Technology \\ Allahabad-211012, (U.P.) India
}

\begin{abstract}
The impact of Information Technology (IT) techniques on Human Resource Management (HRM) in Technical Institutions of India has been studied by conducting case study of $\mathrm{T} 1$ singular-discipline and $\mathrm{T} 2$ multi-disciplinary organizations. The respondents comprise of 82 faculty members, 35 officers and 72 support staff of two technical institutes through well developed and standardized questionnaire. The outcomes of perceptions of human resources of two institutes were also compared with views of external sources such as society, parents and digital media. The opinion for infrastructure facilities related to administration, academics, living complexes and others were rated excellent for the two institutes. The academic related major aspects were found best places in the opinion of respondents for the two institutes. Financial matters such as pay-packages, supporting provisions are some of the aspects found satisfactory of the two institutes. The T2 has excelled in a few parameters whereas $\mathrm{T} 1$ has better place in most of the aspects as opined by respondents, society $\&$ media.
\end{abstract}

This is a generic study and may be applied to most of the educational institutions of India in general and for technical educational institutions in particular with minor customization for individual organization.

Keywords: Information Technology, Human Resource Management, Teaching \& Learning, Performance and Perceptions, Paperless Management, Practices \& Policies, Achievements, Students Services.

\section{INTRODUCTION}

There are a number of success stories [1-5] of human resource management of organizations having variety of natures. This includes institutions in public \& private sectors. In public sector most of the management including Human Resources governed is a close system by various rules of government. Therefore operational flexibility, innovations, diversion from established management norms, financial liberty and other aspects are restricted to a certain extent. Thus to establish landmark or benchmark for establishing success story is different in public sector as compared to similar aspects for private sectors who enjoy almost full operational flexibility of management, innovation, financial freedom and so on with in very broad governance rules. They have therefore, better chance to create a model of success to be followed by others.

In both above systems the educational institutions have their own distinct limitations particularly the organizations of imparting technical programme, as in addition to physical infrastructure common to other type of courses they require excellent laboratories and qualified technical manpower for effective delivery systems. Even in constraint conditions some of the educational organizations have established benchmark globally. In case of technical institutions India has played an important role since ages. The difference lies with the freedom, availability of technical services and linked issues.
There were several achievements in India starting from $18^{\text {th }}$ century till now. In the present work we have studied both success and failure aspects of the institutes established in $21^{\mathrm{st}}$ century $\&$ in $20^{\text {th }}$ century. The first type of Institute is having singular discipline and is called $\mathrm{T} 1$, whereas $2^{\text {nd }}$ Institute having almost all disciplines of engineering i.e. multidisciplinary is called T2. Both institutes are located at Allahabad, U.P. India.

Out of 150 faculty members, 70 officers and 150 support staff, the responses were received from 82 faculty members, 35 officers and 72 support staff. This reflects that more than $50 \%$ of each category responded. In section 2 the important parameters taken for study were discussed. Section 3 gives responses of faculty members, officers and support staff of T1 $\& \mathrm{~T} 2$. Whereas Section 4 represents views of management aspects of the two institutes by external resources including parents of students studying in T1 \& T2, electronic media and society at large. The conclusion of the work has been drawn in Section 5.

\section{THE PARAMETERS}

The quality of human resource management used in determing success and failures are primarily based on the following parameters:

\subsection{Recruitment \& Retention}

There are several ways to recruit manpower in academic institutions. This includes wide circulation of requirement in electronic \& print media. The interests shown by possible incumbents are screened in through competent Human Resources positioned at high levels. After this face to face discussions or remotely/teletalk, final empanelment is made and approved by governing bodies of the two institutes. The identifications of human resources are not localized but are from any part of India/Abroad. The identified Human Resources at the level of faculty/officer \& support systems are offered with pay-package, perks and service conditions as per norms of Government of India as both Institutes under study have been established and are financially managed by federal government. The institutes are not very much liberal in molding the rules for additional financial offers to manpower recruited in the institute. However, in Government service there is a mindset for security of services \& excellent opportunities during service period and after superannuation as well. The vertical growth although limited, most of the manpower employed in these institutes stay for the full service period. There are reasonable facilities for their spouse and children including healthcare, entertainment, clubs, sports, games, residences, possibility for visits abroad, training for enhancing knowledge etc. Such extra support keeps the Human Resources of the two Institutes continue their services and are retained for longest period. The perception of Human Resources inhouse and external ones are discussed in Section 3. 


\subsection{Programmes}

Both institutes being technical ones are offering courses at graduate, post graduate and Ph.D levels. Being different in nature the number of courses in both institutes is different. However, as for as their approaches towards curriculum and its periodic upgradation, delivery through electronic system, unique examination, evaluation systems and knowledge sharing among faculty members and stakeholders etc are concerned both institutes have almost similar mapping with each other. The students are best evaluator of the academic programmes. The two institutes have been rated best by students although T1 scores slightly high (20\%) as compared to $\mathrm{T} 2$. The reason may be that $\mathrm{T} 1$ being established in $21^{\text {st }}$ century has better academic resources.

\section{2.(1) Management (Human Resources)}

Partially some components of this have already been incorporated in section $1,2.1$ and 2.2 above. The HR management an important sector is discussed in section 3 .

\section{2.(2) Academics}

This aspect includes management of students from their preadmission to post declaration of examination results. In India there is a huge aspirant for admission in limited capacity of the two Institutes under study. Before selecting the Institutes the aspirants evaluate the success stories of the Institutes under study and others having premier ones with excellent standing on various parameters. Therefore only brilliant students get accommodated in these Institutes for their education. The syllabus of these Institutes is at par with any Institute globally.

Imparting knowledge, laboratories and its management, examination \& evaluation systems, grading, interpersonal relations between giver \& receivers, academic ambience, maintenance of standards etc are rated high ( $80 \%$ and above) by in-house Human Resources of the two Institutes [1-4].

\section{2.(3) Administration}

Administrative setup for managing all components of the academic organizations has to be entirely different from the management of other organization such as industries, companies and factories including several similar private and public sector establishments. In educational institutions the rules \& norms for maintenance of records is almost similar. However, face to face communication has to be handled in an entirely different manner as faculty members and students are very sensitive segments of the organization. In these aspects information technology is playing very important role in managing their sensitive and personal problems. The IT tools do not require visit of officers to any section for their various classified needs or impressing upon their requirements. The IT has enabled to appreciate the needs of academic sector by administrators and vice-versa, which are normally not there before application of IT in human resources management. The perception index of all Human Resources working with various responsibilities has gone very high with the use of IT tools \& technologies in the two Institutes [5-7].

\section{2.(4) Infrastructure}

It has been observed that good infrastructure comprising of hardware \& software play very important role in serving excellent working ambience in any organization including educational institutions. In case of later ones the administrative building with latest IT enabled facilities, laboratories, comfortable living conditions, sports \& games provisions including tracks, courts, swimming pool etc, entertainment facilities with suitable musical instruments and clubs are important ingredients of an excellent infrastructure. All IT enabled systems require appropriate software for possibility of periodic modifications \& upgradations alongwith competent technical manpower. T1 \& T2, have most of these facilities and are graded as excellent by faculty members, officers, staff and students of both Institutes as per data analysis provided by them.

\subsection{Survey Method}

Human Resource Management for general education institutions has been studied by a number of researchers [514]. The standard questionnaires have been also developed for survey of the opinion of respondent related to such organizations. In case of technical institutes in addition to the facilities in general education institutions for delivery of education \& management require laboratories, equipments, technical staff, maintenance workshops and technical ambience for practical and research work. Therefore, the questionnaire for general education may not be fully applicable in technical institutions. The questionnaire developed for such institutes were circulated to eminent persons and it was standardized by incorporating the suggestions received from them. The questionnaire were different for all the three types of respondent i.e. faculty members, officers \& support staff. The questionnaires were personally handed over to all the respondents and responses received were analyzed by using various techniques of information technology.

\section{IN-HOUSE PERCEPTIONS 3.1. Perceptions of Faculty}

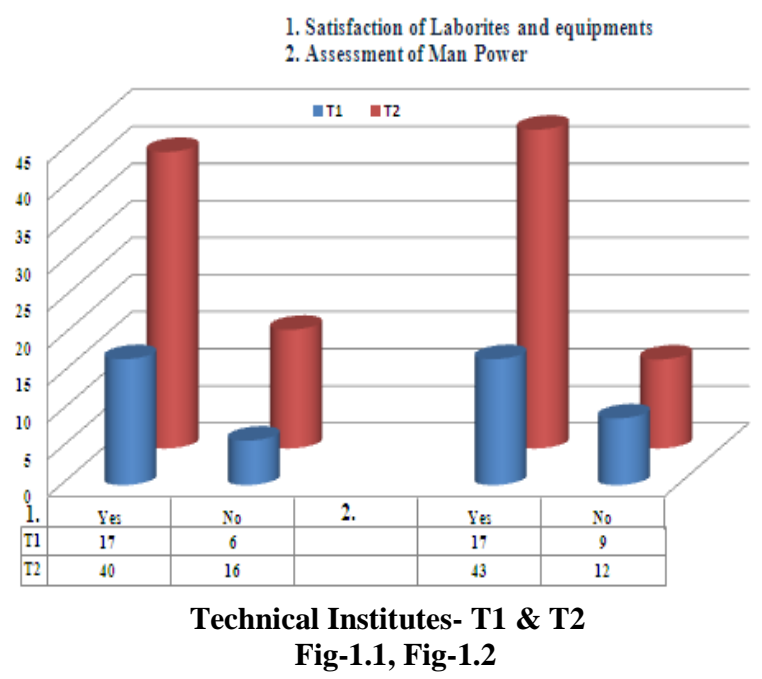

In both Institutes the traditional method of chalk, duster and blackboard system is replaced by electronic media for delivery of education, communication of various notices \& information and management of service records. The provision of availability of academic calendar well before commencement of semester, examination and evaluation practices, continuous assessment, transparency and problem solving sessions through face to face interactions are satisfactory as per perceptions of faculty members of both Institutes. The facilities like laboratories, classrooms, living complexes, provision for extracurricular activities, sports \& games and possibility in participation of conferences alongwith ladder for vertical growth are almost satisfactory index of both Institutes as measured by most of the faculty members. However, T1 being of recent origin has edge over 
T2 in most of the observations by the faculty members. In case $\mathrm{T} 1$ the satisfaction level of faculty members about laboratories and equipments is $74 \%$ whereas in $\mathrm{T} 2$ it is $71 \%$. Rest of respondents i.e. $26 \%$ in case of $\mathrm{T} 1$ and $29 \%$ of $\mathrm{T} 2$ are not fully satisfied. Similarly, in case of figure 1.2 the assessment of manpower is $65 \%$ in $\mathrm{T} 1$ where as in $\mathrm{T} 2$ it is $78 \%$. Rests of the respondents in both institutions do not have satisfaction with the assessment of manpower.

\subsection{Perceptions of Officers}

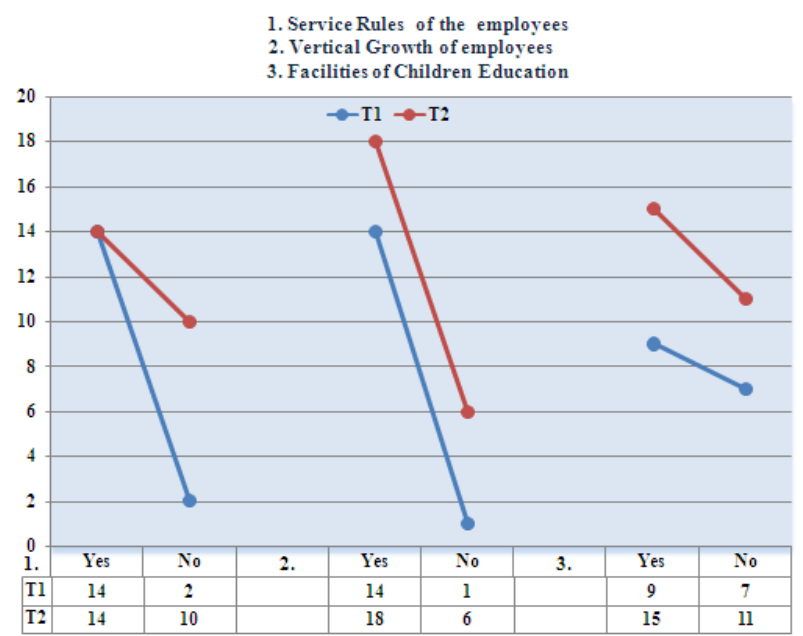

Technical Institutes- T1 \& T2

Fig-2.1, Fig-2.2, Fig-2.3

The recruitment of appropriate person for appropriate job is a difficult task. The perception of officers in this respect alongwith provision of their vertical mobility, various facilities as mentioned in case of faculty members have been also endorsed by officers in almost every item and with the same level of perception. The service rules and conditions including pay-packages, perks, availability of discretionary fund, permanent imprest and periodic training for upgradation of knowledge are satisfying components (Figs 2.1 and 2.2) of majority of officers in both institutes. The stress releasing facilities, entertainment, health care, facilities for children education, uninterrupted power supply, twenty-four hours internet facilities are rated excellent in $\mathrm{T} 1$ as compared to $\mathrm{T} 2$ by officers of two Institutes. T2 being multidisciplinary organization and being of $20^{\text {th }}$ century it had established norms \& traditions for almost every activity related to academic, administrative \& financial aspects and are slightly $15 \%$ better to $\mathrm{T} 1$ as observed by officers. Figure- 2 reflects qualitative percentage of officers about service rules, vertical growth of employees and facilities of education to their children. Figure-2.1 reflects the first aspect as $88 \%$ of the employees of $\mathrm{T}-1$ shown satisfaction about their rules whereas in case of T-2 this number is $58 \%$. The other employees are not very much satisfied with the rules. Figure- 2.2 reflects very good data about the opinion of the facilities regarding vertical growth of employees in $\mathrm{T} 1$ as $91 \%$ and in case of $\mathrm{T} 2$ it is $71 \%$ showing happiness with the growth of their institute. This concludes that $\mathrm{T} 1$ has better planning and prorgrammes to achieve new heights for their developmental aspect. Regarding facilities for education for children of employees in both institutions satisfaction level is about $57 \%$ as reflected in Fig.2.3. Therefore, it reflects that further facilities be created for the kids of the employees to enable them for better education. This is required for greater comfort and facilities to all the employees.

\subsection{Perceptions of Support Staff}

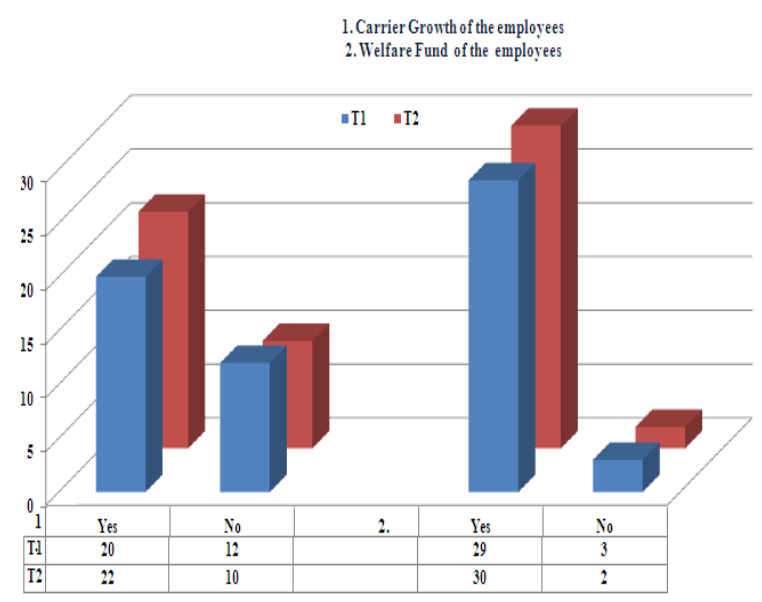

Technical Institutes- T1 \& T2

Fig-3.1, Fig-3.2

The support staff of any organization plays a key role to share various responsibilities in discharging all management aspects of human resources. As per their expectations both institutes have not only made provisions for their career growth, retention and superannuation benefits but also made equal accessibility to all the facilities as mentioned in above paras $3.1(\mathrm{a}, \mathrm{b}) \& 3.2(\mathrm{a}, \mathrm{b})$ In addition to the items elaborated at 3.1 (a,b) and $3.2(a, b)$ for which more than $80 \%$ of support staff agreed with same level of opinion as reflected by faculty members \& officers. The hierarchy level of manpower exists in both institutes \& grouped as A,B,C,D (A being the highest). Most of the category of staff are satisfied (93\%) with the existing career advancement scheme, policy of annual performance appraisal, maintenance of infrastructural facilities and participatory management, safety and security of individual, financial satisfaction, welfare fund and schemes, insurance, allotment of responsibilities of work were expressed excellent (90\%) by majority of support staff of both Institutes (Figs 3.1 and 3.2). There is a variation of level of replies $(62 \%)$ in some of three respondents' i.e faculty members, officers and support staff which may be because of difference of nature of work, responsibilities, difference in pay-packages and partly the status. The commonalities being in majority are more valuable as compared to difference in opinions in a few items [10-14].

\section{EXTERNAL PERCEPTIONS 4.1. Perceptions of Parents}

The children studying in the two institutes are the best feeders about quality of teaching, facilities in laboratories and hostels, games, sports and delivery systems, academic ambience and similar other components existing in the two institutes. The parents often visit the institutes and witness the views personally as expressed by their wards. It has been found that more than $90 \%$ of the parents are fully satisfied, confident and adjudged the institutes at very high level. Every parent not only influences his/her family but atleast 100 other persons of the society including their relatives. This has given the two Institutes a better place in the society. T1 has however, better reputation as compared to T2. This may be because it being of recent origin has comparatively excellent ambience \& management. 


\subsection{Perceptions of Society}

As mentioned above the society is partly influenced by the parents of the students. The admirers of the institutes are at National level. Normally the students are being admitted from 20 provinces (States of India). The feedback given by the students and their parents spread across the country. The main objective of any education is normally to have best job/employment in reputed organizations including both private and public sectors. In this respect $\mathrm{T} 1$ has excelled over $\mathrm{T} 2$ as output of $\mathrm{T} 1$ have been valued better by the employers as compared to T2 outputs. The pay packages by reputed employing organizations are far ahead of $\mathrm{T} 1$ in comparison to $\mathrm{T} 2$. This is a major achievement of $\mathrm{T} 1$ which made its rating as excellent [1.3].

\subsection{Perception of Media}

The ranking of institutes in their respective countries alongwith in global perspective has been undertaken since long. The media both print $\&$ electronic systems play very important role in image building of any institute. The main criteria of ranking of an institute is infrastructure, faculty members \& their achievements through research publication \& citation, campus placement of the students, satisfaction level of human resources and societal perceptions. Sometimes people/societal perceptions dominate over other parameters in judging the relative ranking with other institutions of the country. In the instant Institutes under study, the ranking of $\mathrm{T} 1$ has been quite high within 8 to 15 among 100 top class institutions of the country. Similarly T2 had enjoyed ranking around 20-30 in last three years. In T1 it has been observed that some of the publication [1-3] has been viewed by more than 5 million researchers and place them in first five ranks. There have been several such achievements in various academic spheres of the institutes.

The above aspects of the institutes under study itself speak volume of successes in different spheres of activities and place themselves in the category of excellent Institutes of the country. The possible role of media is an important ingredient in the success stories of $\mathrm{T} 1 \& \mathrm{~T} 2$ although the first one ranks better as compared to second one.

\section{CONCLUSION}

A case study has been conducted for HRM effectiveness and impact of latest tools \& technologies of information technology in the two technical institutes having singular and multidiscipline courses and established in $21^{\text {st }}$ century $\& 20^{\text {th }}$ century, respectively. The inhouse perceptions of the important segments i.e. faculty members, officers \& support staff have been collected through well designed and thoroughly validated 50 questions comprising of relevant facilities, programmes and various infrastructural complexes.

The perceptions of third party were also taken into account to compare with the in-house perceptions. The outside perceptions were of the society and the media. Their perceptions as regards physical infrastructure is found excellent, whereas they have expressed gaps in academic programmes related to inadequate number of teaching staff and courses.

The faculty members are main source of education to make it qualitatively comparable to anywhere in the world. The views of these respondents about curriculum, organizing classes, continuous assessment, examination, evaluation, standardization of results have been rated excellent $(80 \%)$ of both institutes. T1 has about $(20 \%)$ better ranks as compared to $\mathrm{T} 2$ in some of these aspects. The responses about infrastructure for laboratories, classrooms, tutorials, office space, administrative setup, residential complexes and entertainment, sports, games facilities were found reasonably satisfactory $(60 \%)$ and well maintained $(85 \%)$ at both institutes. Almost same perceptions percentage wise have been expressed by officers, support staff, society and the media for both Institutes under study.

As regards recruitment, job responsibilities, provisions for vertical career growth, pay-structure, perks, additional support for conferences, and membership of professional societies have been found slightly better $(20 \%)$ more in T1 as expressed by all respondents.

The officers and support staff are satisfied with the facilities for health care, leave travel concession, provident fund, insurance, bonus and all such provisions by the two institutes. The provision of compensation for children school fee and related expenses of the wards, discretionary support and other such support for emergencies are well extended to all employees in the two institutes, resulting in a high satisfaction level $(88 \%)$.

In short it can be mentioned that in management of human resources the impact of IT is appreciable and the two institutes have taken steps for taking advantage of such facilities in various managerial systems such as communication, maintenance of records, software usages in financial transaction and so on. The study, being first in India for technical institutes, has its own value recognition and acceptance of its contribution through published work alongwith appreciation by other Institutes in India \& abroad.

\section{ACKNOWLEDGEMENT}

The author would like to express her sincere thanks and gratitudes to Dr. M.D. Tiwari, Founder Director of Indian Institute of Information Technology, U.P, India for his kind guidance in completion of this contribution.

\section{REFERENCES}

[1] Seema Shah, J. N. Mishra (2008) "Perspective Statistical Analysis of Officers of Technical Education in India" International Journal of Computer Science and Network Security, Vol. 8, No.12 pp.355-360.

[2] Seema Shah, J N Mishra. (2009) "An Analytical Approach of Faculty Members-On the Frame work of Technical Education in India", International Journal of Computer Science and Network Security, Vol.9, No.4 pp.307-314

[3] Seema Shah, (2009) "A Statistical Predictive Study by the Support Staff of Technical Education in India" International Journal of Computer Science and Network Security, Vol. 9, No.7 pp.194-199.

[4] Seema Shah, M. D. Tiwari (2010) "Service Quality of Financial Network of Educational Institutions in India" The first International Conference on Network and Finance Development, Wuhan, China.

[5] Lakhe, R.R. and Mohanti, R.P. (1994), "Total quality management-Concept, Evolution and Acceptability in Developing Economics", International Journal of Quality and Reliability Management, Vol.11 (9), 09-33.

[6] Madu, C.N. and Kuei. C.H., (1993)," Dimension of Quality Teaching in Higher Institutions", Total Quality Management, Vol.4 (3). 
[7] Harvey, L., (2003), "Students Feedback", Quality in Higher Education, Vol. 9 (1) 01-20.

[8] Naik, B M. (2001), "Need to bring quality movement in Higher Education", Journal of Engineering Education, India, July issue.

[9] Demirbag, M., Tatoglu, E., Tekinkus, M. \& Zain S. (2006), "An Analysis of the Relationship between TQM implementation and organizational Performance", Journal of Manufacturing Technology Management, Vol. 17 (6), 829-847.

[10] Surya Rao. U., pal Pandi A. (2006) "Quality Assurance in Technical Institutions", International Journal of Quality and Productivity Management, USA, Vol.06 (01), 40-48.
[11] Pors, N.O. (2001), "Measuring students" performance and perceptions: empirical studies in different dimensions of quality assurance at a library school", New Library World, Vol. 12, Nos 1170/1171, pp.429-35.

[12] Lee, P. (2002), "Sustaining Business Excellence through a framework of best practices in TQM", The TQM Magazine, Vol. 14 No.3, pp.142-9.

[13] Sakthivel, PB., and Raju, R. (2006b), “An instrument for measuring engineering education quality from students' perspective", Quality Management Journal, Vol.13 No. 3, pp. 23-24.

[14] Meirovich, G. and Romar, E.J. (2006), "The difficulty in implementing TQM in higher education instruction: the duality of instructor/students roles", Quality Assurance in Education, Vol. 14 No. 4, pp.324-38. 